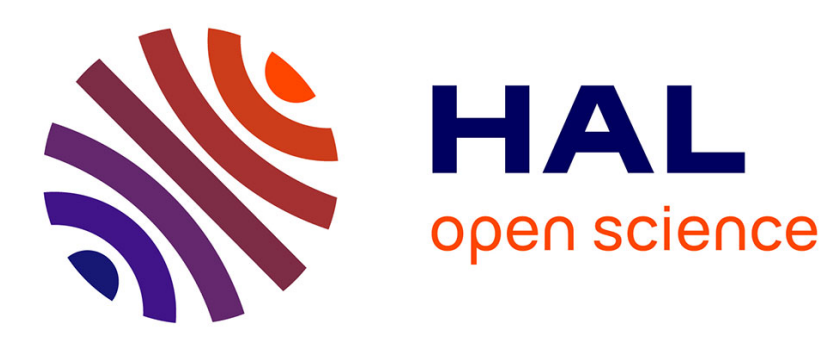

\title{
A New Approach to Analysing and Visualizing the Management of Corporate Innovation Projects
}

\author{
Karolin Gebhardt, Andreas Riel, Tom Maes
}

\section{To cite this version:}

Karolin Gebhardt, Andreas Riel, Tom Maes. A New Approach to Analysing and Visualizing the Management of Corporate Innovation Projects. Walker A., O'Connor R., Messnarz R. (eds) Systems, Software and Services Process Improvement. EuroSPI 2019. Communications in Computer and Information Science, vol 1060. Springer, Cham, pp.756-768, 2019, 10.1007/978-3-030-28005-5_59 . hal-02147806

\section{HAL Id: hal-02147806 https://hal.science/hal-02147806}

Submitted on 5 Jun 2019

HAL is a multi-disciplinary open access archive for the deposit and dissemination of scientific research documents, whether they are published or not. The documents may come from teaching and research institutions in France or abroad, or from public or private research centers.
L'archive ouverte pluridisciplinaire HAL, est destinée au dépôt et à la diffusion de documents scientifiques de niveau recherche, publiés ou non, émanant des établissements d'enseignement et de recherche français ou étrangers, des laboratoires publics ou privés. 


\title{
A New Approach to Analysing and Visualizing the Management of Corporate Innovation Projects
}

\author{
Karolin Gebhardt ${ }^{1,2}$, Dr. Andreas Riel ${ }^{1}$, Dr. Tom Maes ${ }^{2}$ \\ ${ }^{1}$ G-SCOP Laboratory, Grenoble Alps University, 46 av. Félix Viallet, 38031 Grenoble, France \\ ${ }^{2}$ Bayer AG, 51368 Leverkusen, Germany
}

\begin{abstract}
Innovating in a complex corporate context requires managing novelty, risk and uncertainty within an environment that strives for stability, efficiency and profitability on a daily basis. Resolving this conflict confront innovation project (IP) managers with extraordinary difficulties, which are normally addressed using classical project management methods and tools. This paper proposes an approach to analyze and capitalize the power of different project management methods within one IP in order to increase both the probability of success and speed to success. This is achieved based on the classification of project tasks and subtasks according to their uncertainty levels with respect to the design problem and the solution. The success of work packages is assessed against pre-defined output criteria. This methodological approach is complemented by the stakeholder dimension, which takes into consideration the involved stakeholders as well as their relationships and influences in the project. The analysis of an ongoing IP at a leading global industrial player in the life science industry serves as validation platform for the presented tool set.
\end{abstract}

Keywords: innovation project management, agile project management, corporate entrepreneurship, decision aid tool

\section{Introduction}

Innovating in a large and complex corporate organization requires managing novelty, risk and uncertainty within an environment that strives for stability, efficiency and profitability on a daily basis. The structural weaknesses of traditional project management relying on experts capable to predetermine the project execution in detail are becoming aware and more agile and flexible project methods receive encouragement. To cope with the uncertain and changing project needs, innovation projects (IPs) require diverse project management methods over their life cycles. Although the still predominant drive for organizational stability, efficiency and control, there is currently "no conceptual model (...) that enables project managers to understand why different approaches exists, which one to choose, and when." $[1,2,3]$. There is a lack of practical decision aid tools which enable project managers within complex organizations to plan, analyze and track IPs in a highly uncertain environment [4]. 
In this paper, we propose a systematical and practical decision aid tool set basing on the navProM model [5] and supporting managers of IPs in large corporate organizations in analyzing, monitoring and guiding IPs in order to optimize efficient and effective stakeholder integration. The paper is organized as follows: section 2 introduces our research question and the methodology applied to address it. Section 3 investigates substantial related work in corporate entrepreneurship, innovation project management, uncertainty management, and network theory. Section 4 describes the naviProM model with regard to navigating efficiently in project management approaches based on classified project needs. Section 5 proposes our decision aid tool set built upon the hypothesis and the project break down. Section 6 completes the tool set with the integration of stakeholder perspective. Section 7 validates this tool set in a specific industry context based on one concrete IP. Section 8 concludes with a discussion and a summary of the key contributions as well as an outlook on our future research.

\section{Research question and methodology}

In order to provide a decision aid tool that supports IP managers to analyse, understand and model IPs in uncertain environments, this paper addresses the question what are the requirements for such a tool, how to visualize and model it. Thus, the high level of uncertainty (Section 1) has to be reduced as effectively and efficiently as possible to push the project towards a value-adding execution mode characterized by low uncertainty.

Our methodology is based on an exhaustive literature analysis on the subjects of project management, uncertainty management, corporate entrepreneurship, innovation management, and stakeholder integration. This literature analysis is complemented by a field research on the basis of corporate innovation projects. We assume that project management approaches cannot be separated from the specific organizational context and culture, which is why our tool shall cover both the methodological an organizational dimension of IPs.

\section{Related works}

Corporate Entrepreneurship aims at creating a supportive environment for internal IPs. Although its relevance for organizational competitiveness is acknowledged in science and in the industry, very few holistic frameworks exist how to implement IPs [6, 7]. Thereby, IPs are typically characterized by the involvement of a diverse set of network partners and a high level of uncertainty [8]. This level of uncertainty not only changes during IP's lifecycle but also in individual projects and project work packages. Thus, management science constitutes that different levels of uncertainty require different or tailored methodologies $[9,10]$. However, no model exists that guides which approach to use and when [1, 2, 3, 4] or how to build, adapt and apply proven models in the more complex project management [11].

To manage IPs in dynamic and uncertain environments, project managers have to take diverse perspectives, like the task and organization perspective $[12,13]$. There is 
a need to focus IPs to the smallest possible scope to break down the work in digestible work packages [14]. Nevertheless, there is little published research on how to transfer proven decision tools, like the Work Breakdown Structure (WBS), into the applied project management [11].

Furthermore, network management is needed, as entrepreneurs normally do not have the required competences to drive an idea from developing and testing to production and delivery of a final solution. They need to expand their network to get access to complementary assets [15, 16] under a high level of uncertainty [17]. Against this background, scientific findings in role and network theory have identified major roles that have to be represented in IPs $[8,18]$.

\section{$4 \quad$ Project management need classification}

Based on the hypothesis expressed in section 2, we will make use of the two-dimensional model naviProM to capture the project management needs of IP work packages. Spanned on two axes representing the uncertainty regarding the needs respectively the solution the four innovation project management approaches Experiment, Iterate, Plan and Execute are assigned to the four spaces [5]. All four spaces differ through their respective expected inputs (recommended requirements of a method), throughput (signals of right method application), and outcomes (unsatisfying or satisfying) [19].

\subsection{Experimentation}

The naviProM model recommends experimentation when IP teams are confronted with a high level of uncertainty with regard to both defining the problem and developing a solution (input), to gain deeper understanding. Derived from the experiential learning model of Kolb (1984) the approach of experimentation allows rapid, unrestricted learning from the environment as well as the opportunity to pivot $[5,19,20]$. The generation of new insights defines the satisfying outcome of experimentation. Therefore not only the right approach selection (input), also its right application is crucial (throughput). Methods, e.g. Design Thinking [21], are human-centered and problem-oriented. Fast and small learning circles as well as suitable experimentation designs allow project managers to assess this activity. Figure 1 suggests relevant expected inputs and outcomes.

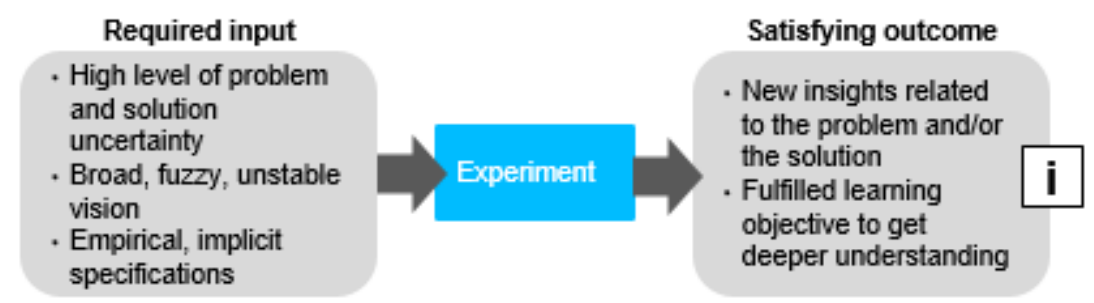

Figure 1: Experiment - input \& satisfying outcome [19]. 


\subsection{Iteration}

If there is a high level of uncertainty related to the needs, however low uncertainty related to the solution iterations are recommended. Iteration-based methods focus on understanding the customer needs and enable continuous, iterative delivery of a working and validated solution (satisfying outcome). Adaptability to change a central characteristic of iteration [22, 23, 24]. Based on a prioritization of learning objectives, the incremental delivery, and ongoing result validation by the customer, the project manager is able to track the right application of iteration [18]. Figure 2 suggests relevant expected inputs and outcomes.

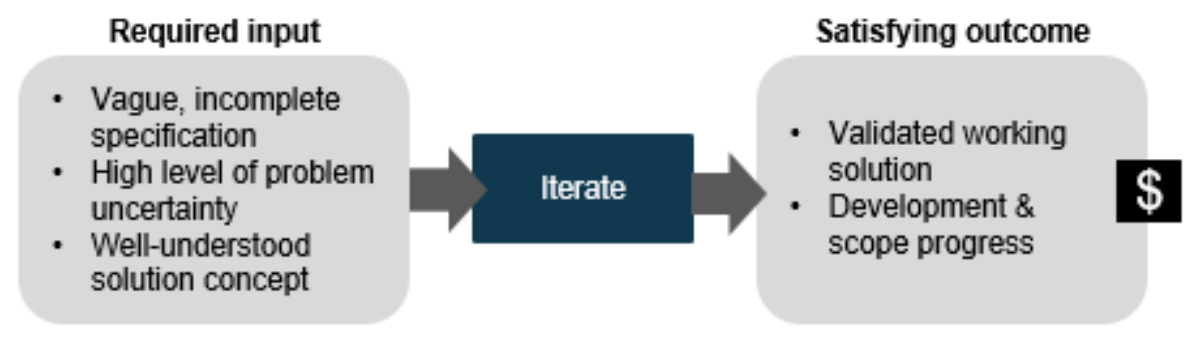

Figure 2: Iterate - input \& satisfying outcome [19].

\subsection{Plan}

Planning is the recommended action mode if the problem is understood but the solution or the way how to solve the problem is highly uncertain. A plan breaks the execution process into standard stages containing prescribed deliverables [18]. Based on the outcome evaluation the manager is able to monitor if the execution takes place as planned and ends in a valuable solution (satisfying outcome) cf. figure 3.

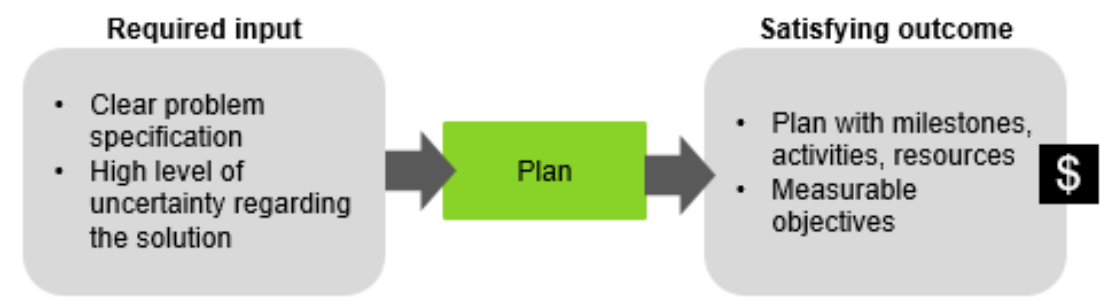

Figure 3: Plan - input \& satisfying outcome [19].

\subsection{Execution}

When the IP team has a clear understanding of the problem and the related solution, execution is recommended [18]. A satisfying solution constitutes the achievement of the defined solution. (cf. figure 4). 


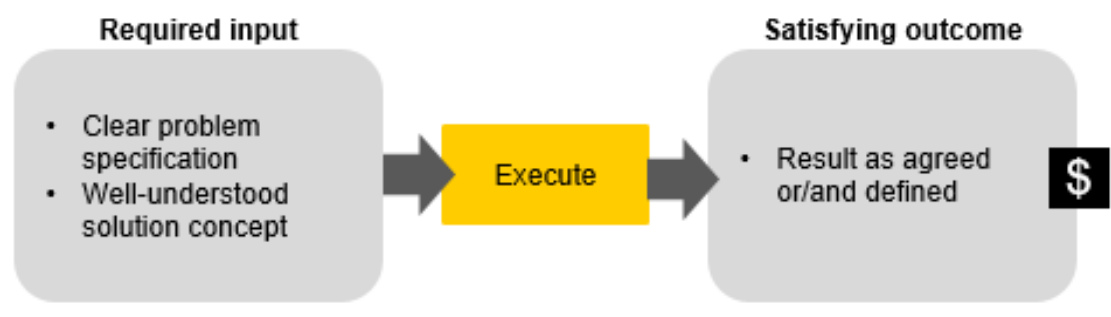

Figure 4: Execute - input \& satisfying outcome [19].

The presented bricks supposed to serve as classification of individual project activities, which support in selecting the most appropriate management approach per task. A satisfying outcome of each activity depends on the applied methodology. A satisfying outcome of execute, plan and iterate constitutes a valuable, working solution whereas for experiment it is a new generated insight and improved understanding. In the following section, we will complement the bricks with a method of structuring IPs in appropriate work packages and tasks.

\section{$5 \quad$ Project work breakdown and reference work packages}

We make use of the concept of the work breakdown structure (WBS) to help IP managers break down the IP to tasks whose input and outcome uncertainty levels can be clearly classified, so that the appropriate management approach can be chosen and applied. The WBS offers a proven way to subdivide a project into subprojects based on individual work packages [25]. The WBS can include a cost and schedule plan of a work package as well as network plan to illustrate the dependencies of work packages [26].

In order to propose generic work packages the model make use of the complemented major objectives proposed by Griffin [19, 27, 28, 29]. Those function as generic reference points of IPs from the initial starting point to the final implementation.

These objectives can be used to analyze and guide ongoing projects, as well as set up new projects. IP managers can derive, analyze or plan work packages and tasks necessary to achieve these objectives and to classify each of them applying naviProM.
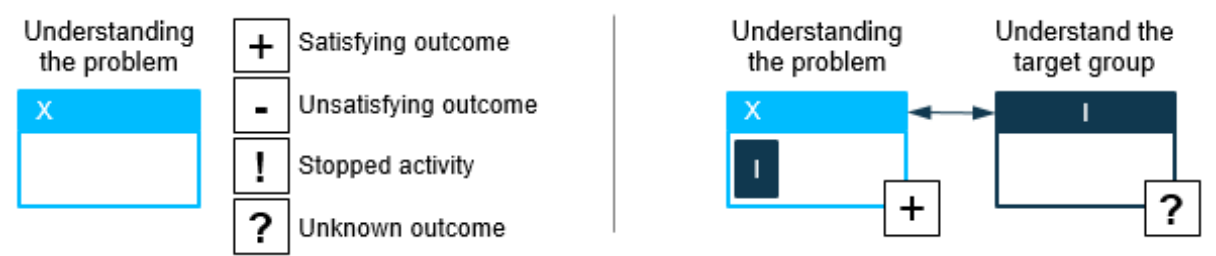

Figure 5: Application of naviProM to major work package objectives

In order to make the decision aid tool set applicable for IP managers, the visualizations presents the workflow on a higher level (cf. figure 5). To easier capture which project management approach was used the work packages are presented without input- 
outcome flow and with color-coded headers (e.g. Experiment $=\mathrm{X}$ in a light blue box) for the naviProM classification. For instance, when a team focuses on the major objective understanding the problem, the naviProM model helps to select the appropriate project management approach how to address this objective (in this case: experimentation) based on the respective input conditions. The successful outcome of an experiment can differ. A satisfying outcome of an experiment is a new insight, whereas for all other approaches it is a value adding solution. Besides the outcome can be either satisfying "“" or unsatisfying "_.", an activity which is stopped before it reaches the defined end point is labeled "!", and a still running activities are labeled "?". The outcome of individual work packages can be mutually dependent (two-sided arrow) or dependent (onesided arrow). Thus, as visualized in Figure 1, the outcome of the experiment regarding "understand the problem" is mutually dependent on the objective "understand target group" as a better target group understanding relates to better problem understanding and vice versa. To address one overarching work package with a specific approach it can be valuable to include subordinated approaches. For instance, a team may decide to use a questionnaire within its experiment design, which they iteratively develop with experts. In this case, the experiment constitutes the overarching approach (light blue "X" brick). The inner brick illustrates the subordinated approach (dark blue "I" brick). That is why within each work package different naviProM classifications can be applied on subordinated work packages.

\section{Stakeholder Integration}

So far, the tool does not include the organizational dimension which is nonetheless an indispensable part of IP success. We therefore complement our tool with the integration of stakeholders involved in each IP work package or task. Derived from the task perspective and based on scientific findings we define three central roles that determine task related progress of an IP:

(1) Core team who drives the project,

(2) Functional expert who complements the required set of expertise, and

(3) User who potentially uses or buys the IP result.

Optionally an IP team may make use of an innovation coach or consultant who supports a team on the methodical level. From an organizational perspective, the IP has to be formally integrated in the permanent organization and has to create a value related to its vision [11]. Newly developed solutions generally do not fit to the established system, require an adjustment of an organization's well-established practices or may eliminate established processes. Thus, IP teams are frequently exposed to active and passive resistance, face resistance as well as political pressure. The level of resistance is particularly high in the period where IP teams and results are integrated into an organization's institutionalized environment as they do not fit to established structures, processes, or habits (e.g. organizational structure, restrictive mindset, lack of competences) [15]. Therefore, the focus is on relationship management between the temporary 
IP and the existing organization. To overcome these difficulties, two further roles are critical for IPs in a corporate context:

(4) Sponsor who provides resources that are not formally implemented as well as project support and protection in demonstrating IP feasibility [30].

(5) Gatekeeper who can provide access to the organizational level and the necessary resources.

Figure 6 shows the presentation of the user, separated in user, customer, and the early adopter, as well as the functional expert, the sponsor, the gatekeeper, and the innovation coach based on notes. To simplify the display of the project flow the core team will not be illustrated as it is involved in each individual work package. In case of an external stakeholder, the note is in a pink frame.

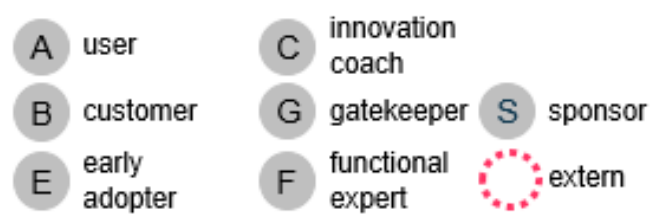

Figure 6: Network roles

Apart from the network roles, the relationships between these roles and the IP are crucial. In particular, under conditions of high uncertainty, when there is no formal organizational acceptance of an idea, dedicated resources are limited. Therefore a team has to start building a network of supporters, of colleagues who are committed to the idea and willing to support the IP team (e. g with their network, expertise, resources). In this case, people do not fulfill their formal function or role, but act on the basis of personal conviction, interest and motivation. They have a positive attitude towards the project. However, people with a negative attitude can have a negative influence on the IP, e. g. through resistance, fear or conflict. To evaluate the influence of stakeholders we differentiate between positive, negative and neutral (cf. figure 7). In addition this influence can differ in its efficiency. Thus, a well-intentioned advice or support can be wrong or not supportive [31]. Therefore, we also rate the efficiency between efficient, neutral or inefficient.

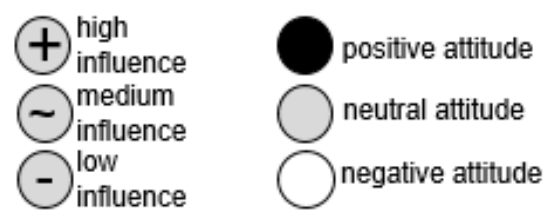

Figure 7: Network relationships

\section{$7 \quad$ Case Study}

We applied the presented decision aid tool set to the analysis of four different IP's at a leading Life science company. In this section, we present the key insights we gained for one selected project to demonstrate the power and potential of our decision tool set, 
whose quantitative evaluation is still ongoing. For confidentiality reasons, we can not disclose project specifics.

The project belongs to a business area having direct access to external end customers. The IP team consists of 5 internal employees, 3 of which have the required domain knowledge and are based in different departments in the same business area, whereas two of them come from IT. Their mission is to develop a mobile software application for global use. Supported by a corporate innovation initiative with funding and consultancy, the prototype reached TRL 4 [32] after a project period of 1 year. While being aligned with business priorities, customer acceptance was not satisfying. In order to help find this problem's root cause, we supported the project manager with our tools set and analyzed the project in retrospect. Figure 8 shows the main outcome.

We identified three main work streams, depicted as grey arrows: customer development (CDW), solution development (SDW), and business development (BDW). Timewise, four phases (blue, overarching boxes) are significant: Phase 1 concentrated on understanding customer needs, phase 2 focused on solution invention as well as business development. During phase 3 the team developed and validated the solution, while the future phase 4 will concentrate on the creation of customer acceptance. Illustrated by the three overarching I-typed work packages, the team first defined the major objectives (green boxes "P") which were iteratively refined over the course of each phase. Only phase 4 did not see any iteration so far. There, the dotted arrows show the aspired interconnection and consolidation of the work streams. The question marks next to the work packages indicate that the latter have not been completed and therefore did not generate any measurable outcome yet. At the beginning of phase 4 customer expectations towards the product are still unclear. In order to find the root cause we analyze the phases 1-3.

In phase 1, the team concentrated its activities on defining the true customer and customer understanding through a chain of experiments. In this case, the adjustment of involved stakeholders is of peculiar interest. In the beginning, two different external target groups (A \& B) were involved whereby A showed a positive and B a negative attitude towards the IP. In the further sequence of experiments the team only involved $\mathrm{B}$ and in later phases $\mathrm{E}$ as it turned out that $\mathrm{B}$ constituted the buying customer, $\mathrm{E}$ the early adopter, and A the end user. This adjustment indicates that experimentation gave the team a better understanding of its customers and product. The strong focus on the potential target group (not involving further stakeholders) shows that the team reduced coordination effort and aimed to learn fast by running small experiments. The experiment to understand the role of early adopters (“!”) was stopped and was restarted in phase 2. The individual work packages in the first phase interact well (double-headed arrows), aiming at understanding the problem and deriving appropriate actions based on a presumably steeply rising learning curve. The major objectives (solution invention $\&$ business alignment) of phase 2 were achieved by again integrating supportive early adopters, as well as a coach and a functional expert to validate the experimental design. The team iteratively developed a first solution draft (with satisfying outcome "+") which served as basis of the later solution development. The results of both the increased customer understanding and the first solution draft were input into the BDW. The team structured the generated results and insights ("P") to later develop a pitch by 
iteration in front of two sponsors (S) and two gatekeepers $(\mathrm{G})$. The "+" indicates that the team achieved the aspired alignment, generating the basis and freedom to act for the downstream work packages.

In phase 3, the team started three separate work packages: (1) validate the solution (by the customer) (2) develop the technical solution, and (3) generate the content. To validate the solution the team used an experiment ("X"-type work package), however generated unsatisfying outcome, indicated by a "-“; as the experiment did not generate the data needed to validate the assumption. The execution of the experiment was planned in advance. In addition to that, the required for questionnaire for the experiment was developed iteratively and validated by two external innovation coaches (C) and one functional expert (F). These involved stakeholders supported the IP positively ("+") and effectively (black node). Although the visualization shows that early adopters (E) and end users (A) were asked early on for feedback, which indicates that the team experimented or iterated the experiment did not generated the required information due to the inappropriate application of the experiment design as well as the lack of integration of the prototype (solution development). At the same time, the iterative development of the technical solution and the content was started independently (few connecting arrows). An external functional expert (F) was involved in developing the content, however the outcome of this work package was unsatisfying ("“-"). The technical development was done in a continuous and efficient exchange with another external functional expert $(\mathrm{F})$. The team regularly validated the results, however without involving the early adopter (" $\mathrm{B}$ " is missing in all work packages). Because of the unsatisfying outcome of the content work package, the interacting technical development work package had to be early terminated ("'!"). Based on the visualization, we can assume that (1) failing to integrate the relevant target group (here the early adopter) in the iteratively solution development, as well as (2) limited interaction between the 3 work packages constitute the main sources of problems generated in phase 3. Nevertheless, it is shown that the level of uncertainty was increasingly reduced and show the importance to shift from experimentation to more execution-oriented approaches. To summarize, our tool creates an overview of the work packages, their stakeholders, as well as their relationships complemented with the rated outcomes on a macro-level. It provides the project manager and team with the insights to quickly capture the project's history, nail down the key problem sources (in this case the lack of user involvement in phase 3 for validation, as well as the lack of interaction between the work packages in phase 2 and 3 ). 


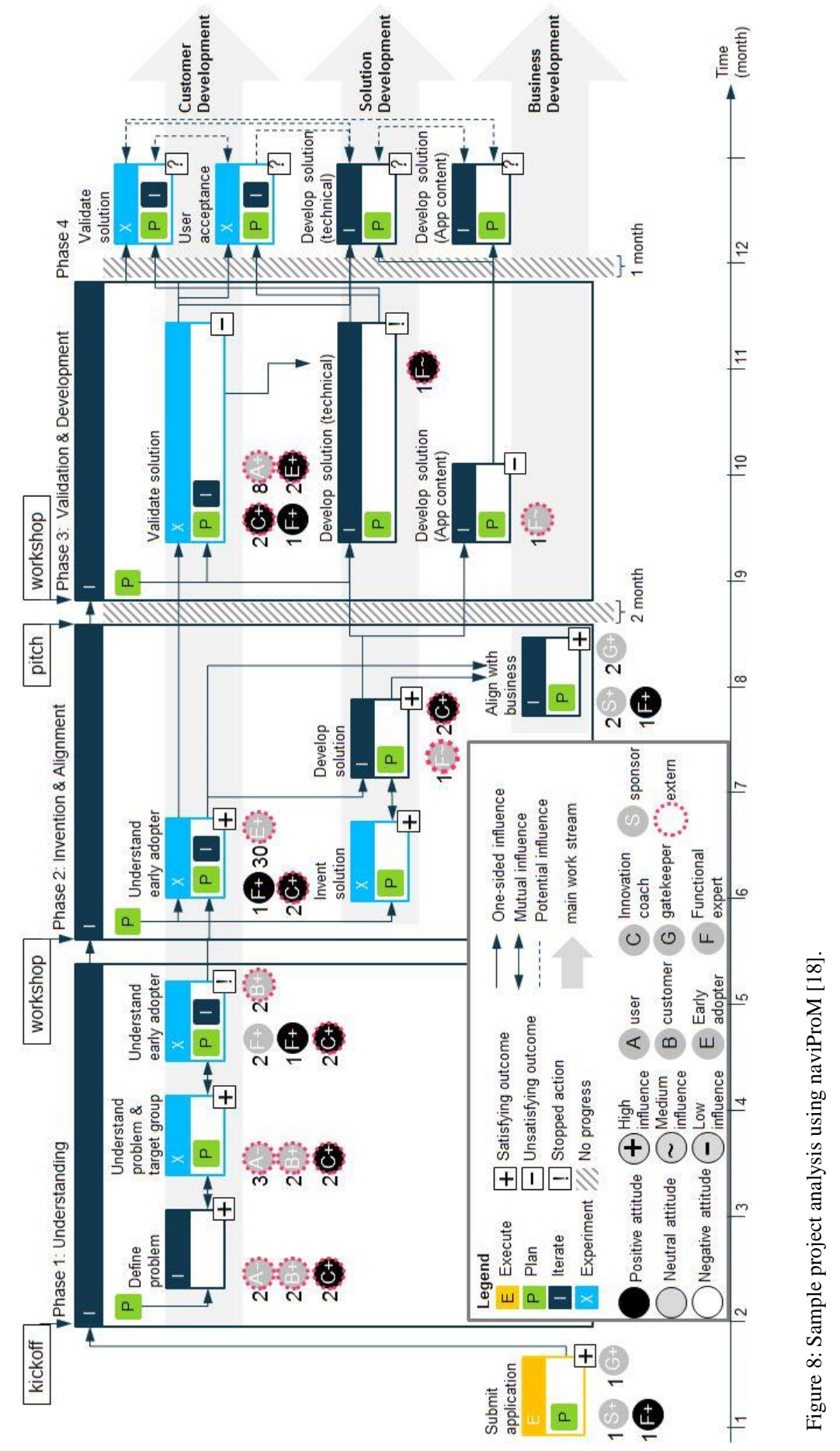




\section{Summary, Conclusion and Outlook}

We have proposed and applied a systematic, complementary decision aid tool set for IP managers to quickly capture the current IP status and in order to understand root causes of challenges and problems and/or to derive future IP activities and stakeholder involvement. In order to optimize speed and probability of project success, the tool integrates project tasks classification and assessment (naviProM) as well as the dependencies and flows among individual work packages. Furthermore, it takes into account the involved stakeholders characterizing their roles and influences. This modular tool kit allows IP managers to analyze and synthesize IPs by proposing work package stereotypes as fundamental IP building blocks. In this paper, we mainly focus on the potential of our approach with respect to the analysis of IPs. Our future focus will therefore investigate IP patterns to complement this future-oriented IP synthesis. Such patterns would provide a completely new support to IP project managers to plan, constantly adjust and guide their IPs with respect to further necessary project tasks and essential stakeholders to be integrated.

\section{References}

1. Pich, M.T., Loch, C.H., De Meyer, A.: On Uncertainty, Ambiguity, and Complexity in Project Management. Management Science. 48(8), 1008-1023. Research Collection Lee Kong Chian School Of Business (2002).

2. Brown, W.J., McCormick, H.W., Thomas, S.W.: Anti Patterns in Project Management. New York: John Wiley (2000).

3. Shenhar, A.: One size does not fit all projects: exploring classical contingency domains. Manage Sci. 47(3), 394-414 (2001).

4. Howell, D., Windahl, C., Seidel, R.: A project contingency framework based on uncertainty and its consequences, International Journal of Project Management. 28:256-264 (2010).

5. Gebhardt, K., Maes, T., Riel, A.: A Project Management Decision Support Tool for Keeping Pace with the Dynamics of Corporate Innovation Projects. European Conference on Software Process Improvement. Springer, Cham. pp. 619-630 (2018).

6. Crawford, G.C., Kreiser, P.M.: Corporate entrepreneurship strategy: extending the integrative framework through the lens of complexity science. Small Bus. Econ. 45(2), 403-423 (2015).

7. Ireland, R.D., Covin, J.G., Kuratko, D.F.: Conceptualizing corporate entrepreneurship strategy. Entrepreneurship Theory Pract: 33(1), 19-46 (2009).

8. Dedehayir, O., Mäkinen, S.J., Ortt, J.R.: Roles during innovation ecosystem genesis: A literature review. Technological Forecasting and Social Change. 136:18-29 (2018).

9. Ramasesh, R.V., Browning, T.R.: A conceptual framework for tackling knowable unknown unknowns in project management. Journal of Operations Management. 32(4), 190-204 (2014).

10. Ciric, D., Lalic, B., Gracanin, D., Palcic, I., Zivlak, N.: Agile Project Management in New Product Development and Innovation Processes: Challenges and Benefits Beyond Software Domain. IEEE International Symposium on Innovation and Entrepreneurship (TEMS-ISIE), Beijing, pp. 1-9 (2018). 
11. Daniel, P.A., Daniel, C.: Complexity, uncertainty and mental models: From a paradigm of regulation to a paradigm of emergence in project management. International Journal of Project Management. 36(1), 184-197 (2018).

12. Andersen, E.S.: Do project managers have different perspectives on project management?. International Journal of Project Management. 34(1), 58-65 (2016).

13. Paluch, S., Antons, D., Brettel, M., Hopp, C., Salge, T.O., Piller, F., Wentzel, D.: Stage-gate and agile development in the digital age: Promises, perils, and boundary conditions. Journal of Business Research (2019).

14. Collyer, S., Warren, C.M.: Project management approaches for dynamic environments. International Journal of Project Management. 27(4), 355-364 (2009).

15. Greve, A., Salaff, J.W.: Social networks and entrepreneurship. Entrepreneurship theory and practice. 28(1), 1-22 (2003).

16. Teece, D.J.: Profiting from technological innovation: Implications for integration, collaboration, licensing, and public policy. In D.J. Teece (ed.), The Competitive Challenge: Cambridge, MA: Ballinger Publishing. pp. 185-219 (1987).

17. Kelley, D.J., Peters, L., O'Connor, G.C.: Intra-organizational networking for innovationbased corporate entrepreneurship. Journal of Business Venturing. 24(3), 221-235 (2009).

18. Markham, S.K., Ward, S.J., Aiman-Smith, L., Kingon, A.I.: The valley of death as context for role theory in product innovation. Journal of Product Innovation Management. 27(3), 402417 (2010).

19. Gebhardt, K., Riel, A., Maes, T.: Corporate Entrepreneurship in Complex Organisations: Towards a Holistic Decision Aid Tool Set to Analyse and Plan Innovative Design Projects. Procedia CIRP Design 29 (2019), in print.

20. Kolb, D.A.: Experiential Learning: Experience as the Source of Learning and Development. New Jersey: Prentice-Hall (1984).

21. Brown, T.: Design thinking. Harvard Business Review; 86(5), 84-92 (2018).

22. Heck, J., Rittiner, F., Steinert, M., Meboldt, M.: Iteration-based performance measurement in the fuzzy front end of PDPs. Procedia CIRP 50. p. 4-19 (2016)

23. de Weck, O.L., Eckert, C.: A classification of uncertainty for early product and system design. International Conference on Engineering Design, ICED, 28-31 August 2007, Paris: Cite des Sciences et de l'industrie (2007).

24. McManus, H., Hastings, D.: A framework for understanding uncertainty and its mitigation and exploitation in complex systems. INCOSE International Symposium, Rochester, NY. 15(1), 484-503 (2005).

25. PERT Cost Systems Design PERT Coordinating Group (Jun 1962) (DOD and NASA Guide).

26. Tausworthe, R.C.: The work breakdown structure in software project management. Journal of Systems and Software. 1, pp. 181-186 (1979).

27. Koen, P., Ajamian, G., Burkart, R., Clamen, A., Davidson, J., D'Amore, R., et al.: Providing clarity and a common language to the 'fuzzy front end'. Research Technology Management. 45, pp. 46-55 (2001).

28. Griffin, A., et al.: Industrial Marketing Management. 43, pp. 1362-1371 (2014).

29. Ries, E.: The lean startup: How today's entrepreneurs use continuous innovation to create radically successful businesses. Crown Books (2011).

30. Tighe, G.: From experience: Securing sponsors and funding for new product development projects - the human side enterprise. J. Prod. Innov. Manag. 15, 75-81 (1998).

31. Hoang, H., Yi, A.: Network-based research in entrepreneurship: A decade in review. Foundations and Trends in Entrepreneurship. 11(1):1-54 (2015).

32. Mankins, J.C.: Technology readiness assessments: a retrospective. Acta Astronaut 2009; 65(9-10), 1216-1223. 